\title{
O uso da fotografia no livro infantil
}

\author{
The use of photography in books for children
}

\author{
Spineli, Patricia Kiss; Especialista;UNESP - Bauru \\ kissspineli@yahoo.com.br \\ Menezes, Marizilda dos Santos; Doutora;UNESP - Bauru \\ marizil@faac.unesp.br \\ Paschoarelli,Luis Carlos; Livre Docência; UNESP - Bauru \\ Icpascho@faac.unesp.br
}

\begin{abstract}
RESUMO
O artigo discute o uso da imagem fotográfica em livros infantis. Faz um levantamento da proporção de livros infantis no Brasil que utilizam a imagem fotográfica, assim como em que categorias de livros são aplicadas. Elabora uma discussão analítica partindo do exemplo do livro Contradança de Roger Mello, argumentando sobre algumas características do uso da imagem fotográfica na literatura voltada para crianças.
\end{abstract}

Palavras-chave: fotografia, leitura de imagem, livro infantil, Contradança.

\section{ABSTRACT}

The paper discusses the use of photographic images in books for children. It identifies the proportion of books for children in Brazil using the photographic image, as well as what categories of books are applied. Elaborates an analytical discussion based on the example of the book Quadrille by Roger Mello, arguing about some characteristics of the use of the photographic image in the literature aimed at children.

Keywords: photography, image reading, books for children, Quadrille.

\section{INTRODUÇÃO}

Mesmo em um mundo permeado por imagens, apreendido visualmente pelo ser humano antes mesmo do uso da linguagem verbal, o sistema educacional ainda prioriza o ensino da leitura verbal em detrimento da leitura não verbal e de seus universos estéticos e simbólicos.

De acordo com Knauss (2006), a cultura visual consiste nas representações visuais e nos processos de visualização da diversidade do mundo das imagens. $O$ autor enfatiza sobre a necessidade de preparar cidadãos que possam compreender e interpretar o mundo não verbal, o que demonstra a necessidade e a importância ímpar da alfabetização visual .

Segundo Kellner (apud SARDELICH, 2006), ler imagens implica em aprender a apreciar, decodificar e interpretá-las, analisando tanto a forma como são construídas e operam em nossas vidas, como o conteúdo que comunicam em situações concretas.

Esse incentivo pode começar desde o pré-livro. Segundo Domiciano (2008), esses livros sem texto, dadas a riqueza das suas imagens e narrativa gráficas, são essenciais para a formação da criança pré-escolar. Para a autora o hábito da leitura não se faz apenas mediante o texto literário verbal, já que as crianças lêem imagens e as utilizam em várias formas de linguagem para expressar essa leitura, por exemplo: narrativas verbais, gestos, sons, brincadeiras, expressão gráfica e jogos simbólicos. 
A fotografia está inserida na cultura visual como um dos meios de expressão mais significativos. O processo fotográfico originou-se e ajudou a consolidar a sociedade da imagem do século XIX ao $\mathrm{XXI}$. A imagem fotográfica primeiramente foi vista como uma forma de registrar o mundo e depois como uma maneira de interpretá-lo. Nesse ínterim, o design gráfico é uma das áreas responsáveis pelo abastecimento de imagens na sociedade da imagem e utiliza a fotografia como linguagem expressiva na transmissão da mensagem.

Já nas décadas de 1920 e 1930 aumentou-se o uso de fotografias em detrimento da ilustração, um embrião do que seria a prática comum do Estilo Internacional (HOLLIS, 2001). Tão logo houve a possibilidade de impressão fotográfica em grande escala o design gráfico percebeu na fotografia um forte elemento de composição e persuasão. Desta forma, a fotografia está atrelada ao design gráfico desde a referência visual até a estratégia de materialização da ideia.

Designers teóricos como Max Burchartz enfatizavam a importância da imagem fotográfica como um dos princípios elementares em um bom design:

A fotografia é a apresentação visual daquilo que pode ser percebido opticamente. A fotografia é altamente eficaz quando usada como material tipográfico. Ela pode aparecer sob forma de ilustração, ao lado de palavras ou como fototexto substituindo as palavras, representando ideias com tal objetividade e precisão que não deixa margens para interpretações subjetivas (Burchartz in Hollis, p. 59, 2001).

Para Ambrose \& Harris (2009) as imagens são fundamentais para a comunicação de uma mensagem e na construção da identidade visual de um projeto, proporcionam drama a uma narrativa e apóiam e complementam o argumento de um texto. Apesar desse argumento, o uso da fotografia em livros infantis ainda é restrito.

\section{O livro infantil e a criança}

Um dos teóricos que mais discutiu o desenvolvimento da criança foi Jean Piaget. Para ele, o desenvolvimento mental da criança, assim como o desenvolvimento físico, direciona-se para um estado de equilíbrio e maturidade (WADSWORTH, 1997).

Piaget determinou estágios no desenvolvimento da criança considerando o aspecto intelectual e o afetivo. Nestes estágios, destacam-se as motivações que levam ao desenvolvimento da criança para suprir uma necessidade, sendo a assimilação do mundo exterior pelo interior uma tendência para acomodar as informações recebidas. Dentre essas assimilações pode-se considerar o contato com livros e a leitura verbal e não verbal.

O quadro abaixo, síntese da proposta de Piaget (WADSWORTH, 1997), apresenta as fases do desenvolvimento infantil e serve de parâmetro e suporte teórico para definição da faixa etária na indicação de leitura infantil: 


\begin{tabular}{|l|l|}
\hline \multicolumn{2}{|c|}{ Fases do desenvolvimento infantil } \\
\hline $\mathbf{3}$ a $\mathbf{6}$ anos & $\begin{array}{l}\text { Pensamento pré-conceitual: construção dos símbolos. Mentalidade mágica. Indistinção } \\
\text { eu/mundo. Pré-leitura: Desenvolvimento da linguagem oral. Percepção e relacionamento } \\
\text { entre imagens e palavras: som, ritmo. Tipos de leituras: Livros de gravuras, rimas infantis, } \\
\text { cenas individualizadas. }\end{array}$ \\
\hline $\mathbf{6}$ a $\mathbf{8}$ anos & $\begin{array}{l}\text { Pensamento intuitivo: Aquisição de conceitos de espaço, tempo e causa. Ainda } \\
\text { Mentalidade mágica. Fantasia como instrumento para compreensão e adaptação ao real. } \\
\text { Leitura compreensiva: Textos curtos. Ilustração necessária: facilita associação entre o que é } \\
\text { lido e o pensamento a que o texto remete. Tipos de leituras: Aventuras no ambiente } \\
\text { próximo: família, escola, comunidade, historias de animais, fantasias, e problemas infantis. }\end{array}$ \\
\hline $\mathbf{8}$ a $\mathbf{1 1}$ anos & $\begin{array}{l}\text { Operações concretas: Pensamentos descentrados da percepção e ação. Capacidade de } \\
\text { classificar, enumerar e ordenar. Leitura interpretativa: Desenvolvimento da leitura. } \\
\text { Capacidade de ler e compreender textos curtos e de leitura fácil, com menor dependência } \\
\text { da ilustração. Orientação para o mundo. Tipos de leituras: Fantasia. }\end{array}$ \\
\hline
\end{tabular}

De acordo com o estágios do desenvolvimento etário da criança, Santos \& Navas (2002) sintetizam as sugestões literárias:

- 15 meses: livros que estimulam o tato, olfato, audição e visão.

- 2 a 3 anos: livros com figuras grandes, situações do dia-a-dia.

- 4 a 5 anos: livros com repetição de frases, com imagens grandes.

- 6 e 7 anos: contos de fada e poesia.

- 8 e 9 anos: comunicação objetiva, com seqüência lógico-temporal

- 10 a 11 anos: livro de herói e com menos imagens.

Azevedo (1999) classifica os livros em didáticos, paradidáticos, livros-jogo e livros de imagem. Os didáticos são essencialmente utilitários, com informações que pretendem transmitir conhecimento e informação. Os paradidáticos são utilitários como os didáticos, mas abordam assuntos paralelos às matérias do currículo regular. Os livros-jogo pertencem ao mundo dos jogos e utilizam o livro como suporte. Os livros de imagem são aqueles que contam histórias através de imagens, abdicando do texto verbal. Para fins de análise, no presente trabalho foram considerados livros paradidáticos e livros de imagem.

\section{As imagens do livro infantil}

O termo imagem origina-se do latim imago e significa a representação visual de um objeto. Segundo Santaella \& Nörth (1999) há dois domínios para o mundo das imagens: (1) representações visuais, tais como ilustrações, fotografias, gravuras; e (2) domínio imaterial das imagens em nossas mentes.

Santaella \& Nörth (1999) também fazem uma classificação da imagem sob os paradigmas préfotográfico, fotográfico e pós-fotográfico. No paradigma pré-fotográfico as imagens seriam artesanais, requerendo habilidade manual, perecíveis pelo manuseio e suporte e gerando cópia única. Nesse tipo de produção estão as pinturas e esculturas. No paradigma fotográfico, as imagens são ópticas, com necessidade de um referente visual, produzidas em suporte fotossensível que reage a luz (emulsão do filme) e passíveis de reprodução, como a fotografia, cinema, televisão. No pós-fotográfico estão as imagens sintéticas produzidas através de cálculo matemático em um computador - suas relações são numéricas e não necessitam do aparato óptico uma vez que são criadas a partir de modelos moduláveis, compostos por pixel - o menor ponto que forma uma imagem digital. O suporte é a visualização em um monitor. Seguindo a classificação de Santaella \& Nörth (1999), a ilustração seria uma imagem préfotográfica e a fotografia uma imagem fotográfica.

Para Domiciano (2008), na literatura infanto-juvenil, a ilustração passa a ter um papel de grande destaque, sobressaindo-se muitas vezes ao texto. É necessário ressaltar, no entanto, a diferença entre o livro com ilustração, em que a imagem é apoio e somente reforça o texto, e o livro ilustrado, em 
que não existe a palavra escrita ou esta atua juntamente com a ilustração. Nos livros infantis há a predominância da ilustração nas mais diversas linguagens gráficas, desde ilustrações com alto poder de verossimilhança à ilustrações mais abstratas.

Werneck (1986) argumenta que tanto as ilustrações ricas em detalhes (realistas ou não) quanto as mais simbólicas são importantes para o desenvolvimento visual da criança. Uma está mais relacionada à análise e outra à síntese. As ilustrações realistas contribuem para o desenvolvimento intelectual da criança, as simbólicas para o desenvolvimento da imaginação.

Dubogel (apud Domiciano, 2008) relata que, a despeito de algumas pesquisas mostrarem que as crianças tendem a gostar mais de ilustrações realistas, essa preferência parece surgir da prática e do hábito já constituído pelo processo de socialização, uma vez que são as crianças maiores que apresentam essa tendência.

Dentre aos estilos ilustrativos no livro infantil, Camargo (1998) enumera:

Quanto a construção: linear com a valorização da linha, ou pictórico com valorização das expressões visuais provocadas pelas formas e volumes;

Quanto ao plano: o reforço da bidimensionalidade ou a profundidade com ênfase à representação da tridimensionalidade;

Quanto a forma: fechada em que a ilustração encerra-se em si mesma, está completa ou aberta em que a ilustração permite a percepção de outros elementos fora da cena central;

Quanto aos elementos: pluralidade, a imagem mostra múltiplos elementos, ou unidade a ilustração leva a uma coesão visual através de algum elemento;

Quanto a representação: clareza, elementos visuais claramente representados ou obscuridade com a abstração, ou representação parcial de elementos.

O objetivo do presente artigo é discutir o uso da imagem fotográfica em livros infantis, partindo de um levantamento da proporção de obras brasileiras que utilizam fotografias, e usando como exemplo para a análise o livro Contradança de Roger Mello.

\section{MATERIAIS E MÉTODOS}

Foi realizado um levantamento de 600 livros infantis na sessão de livros infanto-juvenis nas faixas etárias de 15 meses a 11 anos da Livraria Cultura do Conjunto Nacional de São Paulo. Os livros levantados consistiam de paradidáticos, livros de imagem e literatura infantil com texto verbal - o objetivo foi verificar a quantidade de livros que utilizavam fotografia como recurso imagético. Após o levantamento quantitativo foi realizada uma leitura analítica do livro Contradança de Roger Mello (2011) utilizando o conceito de significantes plásticos e significados (JOLY, 2000) para verificar como a linguagem fotográfica foi usada como recurso gráfico. A leitura analítica foi construída tendo por base os elementos da linguagem fotográfica.

\section{RESULTADOS}

\section{Proporção de livros infantis com fotografias}

O presente artigo trata de livros infantis destinados à faixa etária entre 15 meses e 11 anos, pois segundo algumas classificações etárias de leitura (SANTOS;NAVAS, 2002), para leitores acima de 11 anos são produzidos livros com menos imagens. A separação da faixa etária para leitura é um referencial, não um fator limitante. $O$ arcabouço dessa pesquisa traz uma amostra da literatura infantil publicada no mundo e editada no Brasil para se chegar a uma relação de proporção entre os livros com imagens de ilustração e os de fotografia.

Por utilizarem a mesma linha de projeto de design, as coleções não foram contadas como peça individual, mas como obra única, já que também não será feita uma análise crítica dessas obras, por esta se tratar de uma pesquisa quantitativa.

Dos 600 livros infantis verificados somente 30 utilizam a imagem fotográfica como recurso gráfico, equivalendo a 5\% do espaço amostral. Destes, 12 títulos são adequados para crianças maiores 
de 11 anos, com maior orientação para o real e estruturas lógicas do pensamento (WADSWORTH, 1997). 1,3\% do espaço amostral correspondem a livros para crianças abaixo de 11 anos, mas com alguma carga didática, voltados ao aprendizado dos animais, dos países e das pessoas, ou seja, não há necessariamente uma narrativa. Somente $0,3 \%$ dentre os 600 livros pesquisados utilizam a imagem fotográfica como expressão para uma narrativa ficcional.

Provavelmente o $1,3 \%$ de livros com carga didática utilizando imagens fotográficas, não classificados como didáticos, esteja atrelado ao fato da fotografia ainda ser vista como atestado da realidade e mimese do real. Quando se quer tratar das coisas como realmente são no mundo, recorrese a imagem fotográfica.

Foi observado que uma quantidade significativa de livros infantis utiliza a ilustração realista, próximo a uma imagem fotográfica, mas com linguagem de ilustração.

Apesar da pequena quantidade de obras utilizar a imagem fotográfica, nota-se que ilustrações de estilo mais realista são abundantes. Desta forma, pode-se inferir que a linguagem realista sobrepuja o uso da fotografia, ou seja, prefere-se uma ilustração mais realista do que uma imagem fotográfica. No entanto, para criança não é necessário a verossimilhança para que ela aceite e perceba o livro, caso contrário, o recurso fotográfico seria mais empregado nas edições infantis.

Uma possível explicação para isso seja a de que a ilustração é mais associada ao universo infantil. Essa é uma percepção construída culturalmente. A estética da ilustração está associada a fantasia e a imaginação, enquanto a imagem fotográfica ainda está calcada na idéia do realismo, da cópia da realidade. Apesar de não ser o escopo de investigação desse trabalho, observou-se que a partir da pré-adolescência aumenta o uso de imagens fotográficas nos livros ficcionais (particularmente na capa) talvez por conta do pré-adolescente já ter desenvolvido processos mentais mais complexos e associações mais calcadas na realidade. Nessa categoria se observou fotografias em livros que são subprodutos de programas televisivos ou filmes, o que justificaria o uso de imagens fotográficas dos personagens.

Também se utilizam imagens híbridas, como ilustrações com fotografia e imagens fotográficas manipuladas, que adquirem a estética da ilustração. No entanto, esse trabalho se manteve no escopo da fotografia pura, sem maiores interferências.

\section{Análise do livro Contradança}

O livro infantil Contradança de Roger Mello (2011) utiliza a fotografia como expressão gráfica. A composição da narrativa é realizada através da linguagem sincrética em que há elementos textuais com elementos imagéticos. O livro foi indicado ao prêmio Hans Christian Andersen 2010, considerado o Nobel da literatura infantil. Seguindo a classificação de Santos \& Navas (2002), seria indicado para a faixa etária de 6 a 10 anos.

Na narrativa uma menina e um macaco brincam de se mirar em uma loja de espelhos. As imagens fotográficas ilustram o texto e ambos sugerem a ideia de que cada um possui várias identidades (ou reflexos).

Segundo Hunt (2011), o livro ilustrado é a única área da literatura infantil que evoluiu do "texto realista clássico para o genuinamente descontínuo e interativo" pelo fato de possibilitar experimentação e inovação, tanto de conteúdo como de suporte: formatos inusitados, diferentes técnicas de imagem, tipologia criativa e narrativas não lineares, abertas a várias interpretações. Apesar do livro Contradança não ser classificado como livro de imagem, observa-se que tanto na narrativa verbal quanto na não verbal há a possibilidade de interpretação polissêmica e o uso da fotografia como inovação. O livro também apresenta uma proporção maior de imagens em detrimento do texto.

Apesar da presente análise contemplar a comunicação visual apenas na questão imagética, há a necessidade de se pontuar que as imagens acompanham um texto e transpõe visualmente o que está escrito na página, portanto a narrativa é tão textual como imagética.

Na estruturação do livro a cada dupla de páginas há um texto e uma imagem que o complementa e o ilustra - apenas nas páginas 24 e 25 a fotografia da personagem bailarina ocupa as duas páginas sem nenhum texto. As personagens principais são apresentadas nas primeiras páginas. $O$ recurso utilizado 
é o da fotografia em contraluz, resultando em um efeito semelhante à uma ilustração em silhueta (Imagem 1). O livro é finalizado utilizando esse mesmo recurso, trocando um dos personagens. Para a caracterização dos personagens recorre-se a bonecos articulados, enquanto os objetos de cenas são espelhos e alguns móveis. A representação dos motivos é de caráter figurativo.

Em algumas imagens o resultado estático da fotografia permite que esta seja lida quase como ilustração. Pelo contexto da produção sugere-se uma fotografia, mas o aspecto aparenta ilustração.

Foi observado que na capa dois e nas duas páginas inicias da narrativa são utilizadas ilustrações isoladas que sintetizam o universo da história. São imagens da bailarina, do macaco e dos espelhos. Há uma imagem híbrida de desenho com fotografia na página 19 (Imagem 2), porém a maioria é de imagens fotográficas.

O objetivo do artigo foi realizar uma análise do livro focando no discurso construído pela fotografia. Para isso, foram detectados e analisados nas imagens aspectos da linguagem fotográfica como: cor, composição, plano, iluminação, perspectiva, ângulo, foco, movimento, textura e distorções e as possibilidades de comunicação oferecidas por esses aspectos. Os elementos da linguagem fotográfica são considerados os significantes plásticos e o discurso gerado por eles são os significados (JOLY, 2000).

Composição: Para a composição foi aproveitado o formato retangular, padrão da fotografia em $35 \mathrm{~mm}$. O formato do livro de $215 \times 270 \mathrm{~mm}$ (tamanho fechado) permitiu que em páginas duplas fosse explorado o efeito panorâmico. Também há evidência de algumas regras compositivas como seção áurea e regra dos terços.

Plano: o plano diz respeito ao enquadramento do motivo fotografado. $O$ uso dos planos no livro restringiu-se a plano médio e plano geral. Quando a intenção era evidenciar alguma personagem recorria-se ao plano médio, já que nesse tipo de enquadramento o sujeito preenche o quadro da linha do pé ao topo da cabeça ou cortando o sujeito pela cintura. Quando havia a necessidade de mostrar não somente personagem, mas também os aspectos do ambiente, utilizava-se plano geral, que permite enquadrar sujeito dentro de um espaço.

lluminação: na iluminação constata-se o uso da luz lateral e do contraluz. A luz lateral proporciona e realça o volume das formas retratadas, já que a luz incide na lateral do objeto provocando um efeito de claro-escuro. O contraluz evidencia a silhueta do motivo fotografado, a luz incide por trás do objeto e isso faz com que sua parte frontal fique parcialmente ou totalmente escura. No caso analisado, quando há o emprego do contraluz a imagem se assemelha a uma ilustração, pois com a silhueta bem demarcada e a parte frontal totalmente escurecida ocultam-se os detalhes e ressalta-se o grafismo.

Perspectiva: auxilia a indicação da profundidade e da forma, cria a ilusão de espaço tridimensional determinado a partir de um ponto de convergência que centraliza a linha, ou as linhas principais da fotografia. No livro a maioria das imagens apresenta perspectiva, salvo as páginas $30 \mathrm{e}$ 31 , que compõem os elementos em um mesmo plano e achatam a imagem provocando um grafismo, isto é, os elementos compositivos criam formas que eliminam a aparência da perspectiva ressaltando a planura.

Ângulo: esse aspecto diz respeito a posição do fotógrafo/máquina em relação ao motivo fotografado. No livro as imagens estão no mesmo ângulo de visão do fotógrafo, na mesma linha dos olhos e situação de plongée (de cima para baixo) e o contra plongée (de baixo para cima).

Foco: há a predominância do foco contínuo, em que todos os planos estão em foco. Algumas imagens apresentam foco seletivo, em que ou primeiro plano ou segundo plano estão em desfoque.

Movimento: na captura de movimento, apenas uma das imagens do livro apresenta movimento evidenciado, em que são capturadas várias etapas do(s) elementos fotografados. A maioria das imagens apresenta movimento congelado, resultando em uma imagem estática e equilibrada.

Cor: as imagens são capturadas em preto e branco e nuances de cinza, em que é possível perceber a variação de intensidade da gradação tonal entre luz e sombra, produzindo suas diferentes nuances. A cor verde participa como fundo da composição.

Textura: Em algumas imagens o modo como a luz refletiu sobre os objetos provocou variações que podem ser lidas como texturas. Em uma mesma cena é possível observar composições com 
diversificadas texturizações.

Distorções: não foram detectada imagens que apresentem distorções de cor ou forma.

Como discurso, os elementos da linguagem fotográfica abordados acima, favoreceram a criação do ambiente onírico proposto pela história verbal. O uso do plano geral permitiu que em algumas cenas vários reflexos fossem captados em vários espelhos, apesar de registrar um referente físico - neste caso, a fotografia permitiu o retrato de um ambiente mágico, sem referente de realidade (páginas 16 e 18, Imagem 3). 0 uso do preto e branco também é responsável por essa retirada da carga realista, já que transforma cores em nuances de cinza, criando um recurso poético que privilegia a expressividade da cena (a cor poderia chamar a atenção para a realidade que não está presente). Os ângulos tratados nas cenas procuram inserir a visão da criança, colocam o leitor como observador de cena e a variação angular remete aos diferentes pontos de vista abordados na narrativa (Imagem 4).

A idéia de se trabalhar com alguns desfoques também favorece a criação de um clima não real, uma vez que o desfoque retira a carga de atenção de um objeto, deixando-o meio velado e obscuro e privilegiando a ação de um outro objeto de cena. Isso favorece a visão seletiva, não desprezando as outras ações de cena. $O$ foco contínuo, em contrapartida, acentua o mesmo grau de importância a todos os elementos da imagem (Imagem 4). A ênfase da textura obtida em algumas cenas, assim como o efeito de planura (Imagem 5) proporcionam um efeito plástico que colabora para o aumento do repertório gráfico da criança. Aproximar a criança de diferenciados efeitos gráficos pode lhe proporciona um contato maior com a plasticidade da imagem e promover uma educação visual ampla, capacitando a criança a entender as diferentes formas de expressão de sua cultura.

A magia da narrativa de Contradança fica por conta dos motivos tratados na fotografia: os ambientes são realistas (uma casa) mas os personagens são brinquedos. Esse recurso retira a criança da realidade e a leva a um mundo de fantasia.

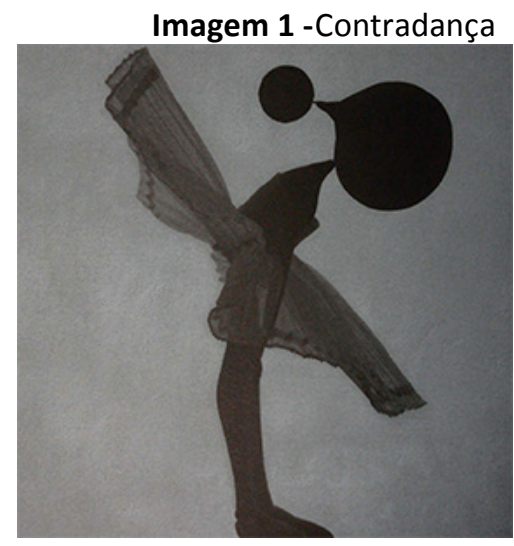

Fonte: Reprodução, Roger Mello (2011, p.12).

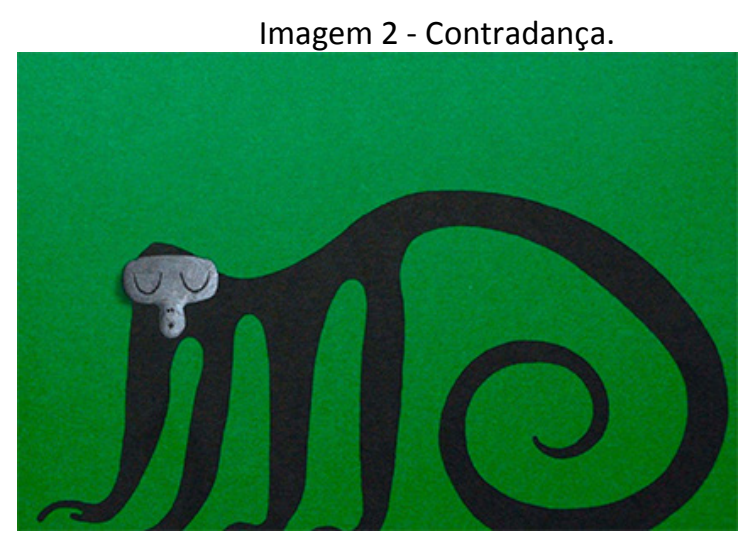

Fonte: Reprodução, Roger Mello (2011, p.19).

Imagem 3 - Contradança 


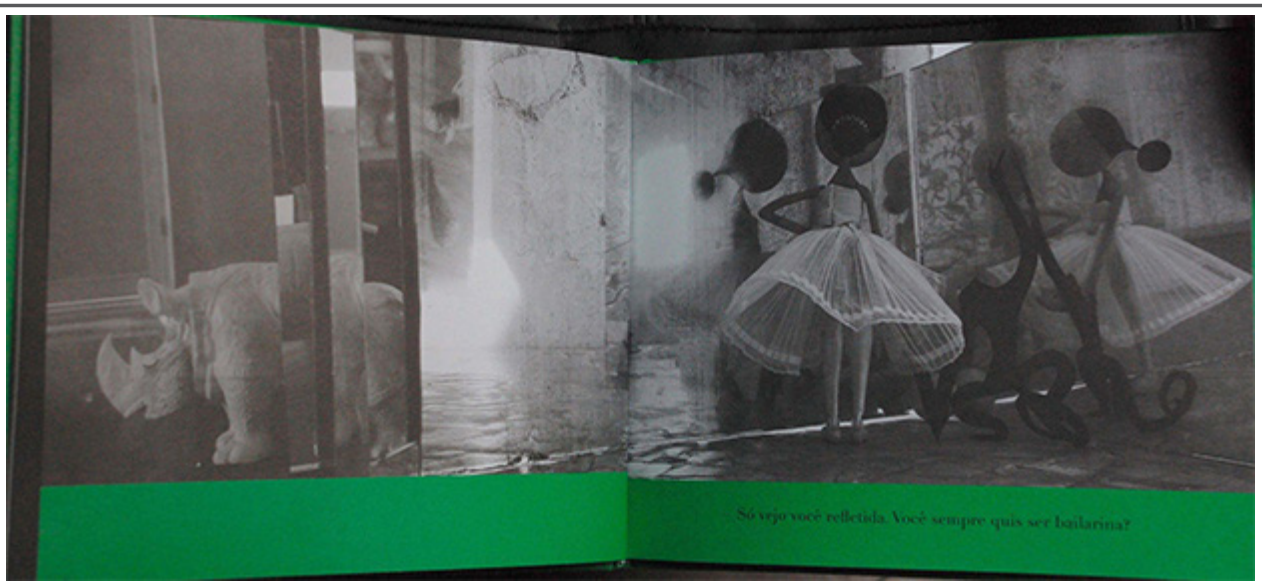

Fonte: Reprodução, Roger Mello (2011, p.16 e 17).

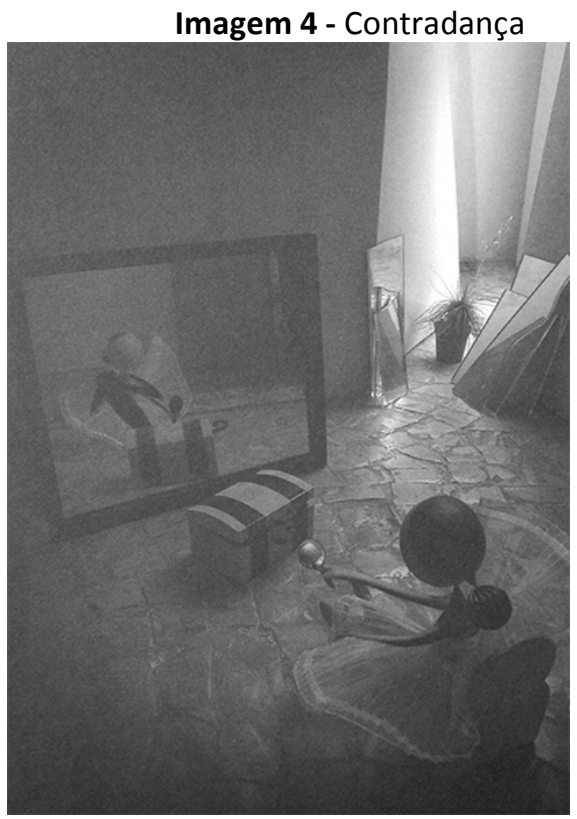

Fonte: Reprodução, Roger Mello (2011, p.21).

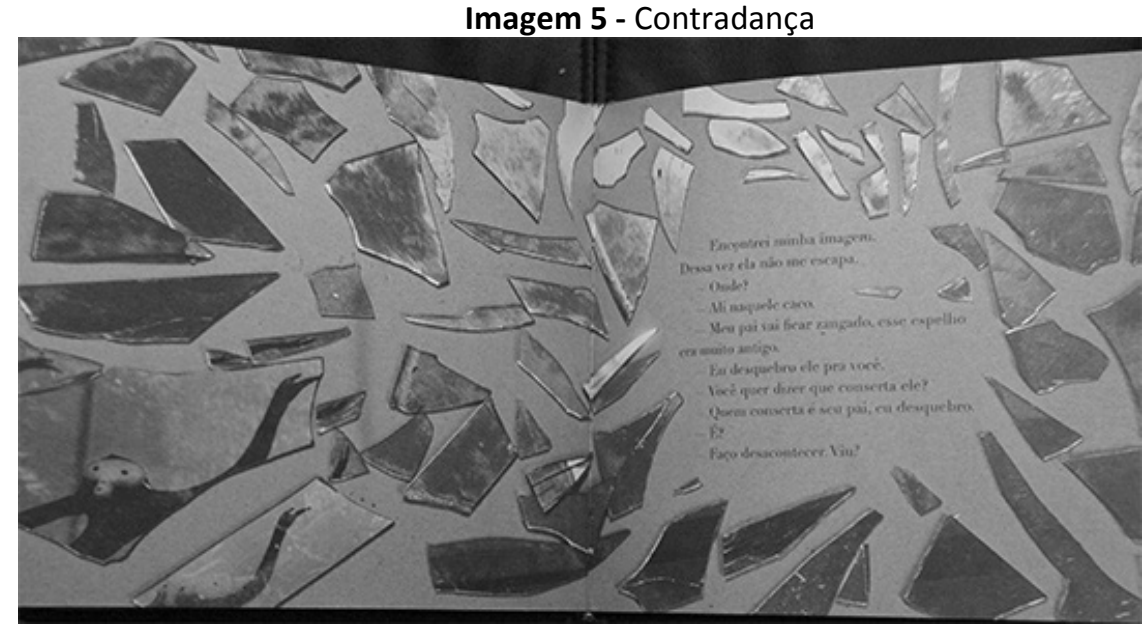

Fonte: Reprodução, Roger Mello (2011, p.30 e 31). 


\section{A fotografia como discurso nos livros infantis}

Para Werneck (1986), a criança à partir de suas experiências prévias é capaz de comparar, discriminar, recriar e interpretar a imagem. Ela acostuma-se com a diferença entre a realidade e a sua representação. Apesar da linguagem fotográfica estar ainda atrelada a uma visão realista e de mímese, vemos pela obra de Mello (2011) que é possível realizar um discurso artístico utilizando-se da estética fotográfica.

Pode-se ainda considerar que as diversas técnicas de ilustração, como definidas por Camargo (1998), enriquecem o universo visual da criança e estimulam sua percepção e sua apreciação estética. Extrapolando para a imagem fotográfica, a técnica fotográfica também poderia contribuir para o estimulo e apreciação estética da criança. Nesse contexto, os estilos ilustrativos proposto por Camargo podem ter algumas de suas características transferidas para a linguagem fotográfica.

No plano, a fotografia por excelência promove a profundidade ou pode valorizar a planura através do achatamento dos planos. Na representação, a fotografia oferece tanto elementos visuais figurativos quanto a captura de formas abstratas. Pela possibilidade de aproximações e afastamentos pode-se tratar de elementos únicos e múltiplos em uma cena dependendo do enquadramento empregado. $O$ mesmo argumento vale para a forma fechada, quando se restringe a um só elemento de cena, ou aberta quando se enquadram outros elementos de cena. Ainda quanto a construção, na fotografia pode-se evidenciar a abstração, através de registros de motivos mais geometrizados com a valorização de linhas, por exemplo, ou o componente pictórico, com a valorização das expressões visuais provocadas pelas formas e volumes.

Não obstante, a fotografia no livro infantil poderá ser incorporada utilizando processos híbridos, integrando fotografia, pintura e ilustração. Deve se considerar que se o tratamento visual adotado originalmente nas fotografias não harmonizar com o espaço imaginário idealizado para o livro infantil, as imagens fotográficas poderão ser retocadas e manipuladas digitalmente através de softwares gráficos, não necessariamente sendo obrigatória a aplicação da fotografia em seu estado "puro". Pode-se haver a alteração de cores, luz inserção de efeitos e filtros para adequar as fotografias a estrutura conceitual do livro. Assim como a ilustração, a imagem fotográfica também não precisa ser utilizada como mímese da realidade. Como supracitado, através de um registro fotográfico pode-se trabalhar com distorções e abstrações.

Há ainda outros fatores que podem ser levados em conta quando do uso de imagens fotográficas na literatura infantil. Dependendo da produção e objetivos propostos pela obra, por exemplo, a fotografia poderá ser um recurso mais rápido para a produção. A imagem fotográfica é uma ferramenta útil também para proporcionar à criança noções de dimensão, proporção e cor.

Pelas indicações literárias de acordo com o desenvolvimento etário da criança apresentadas por Santos \& Navas (2002) e as propostas de Piaget (WADSWORTH, 1997) para os estágios do desenvolvimento infantil acredita-se que a imagem fotográfica pode ser inserida em projetos de livros ficcionais especialmente para crianças de 3 a 11 anos. Esta é uma fase em que, segundo esses autores, o trabalho com a imagem é fundamental, seja para a criança conseguir fazer relações entre texto e imagem ou para estimular a fantasia.

\section{Considerações Finais}

Considera-se que antes de se propor um produto livro para crianças há a necessidade de se realizar estudos e pesquisas detalhadas sobre imagens e propor a melhor linguagem visual para aquela situação. A consideração do uso fotográfico se insere nessas possibilidade de uso de imagem. Seria coerente se desvencilhar de vícios imagéticos e estereótipos de que a criança prefere somente ilustrações. Apesar da ilustração ter sido instituída como pertencente ao universo infantil, ela não é o único recurso de comunicação não verbal.

A estética adotada no livro "Contradança" sugere que é possível utilizar a fotografia como 
Spineli, Patricia Kiss; Menezes, Marizilda dos Santos; Paschoarelli,Luis Carlos

linguagem visual para assimilação infantil, gerando, com esse tipo de imagem, um universo de imaginação para a criança.

\section{Referências}

AMBROSE, Gavin \& HARRIS, Paul.Imagem. São Paulo: Editora: Bookman, 2009.

AZEVEDO, Ricardo. Livros para crianças e literaturas infantil: convergências e dissonâncias.1999. Disponível em http://www.ricardoazevedo.com.br/palestras.htm, acessado em julho de 2011.

CAMARGO, Luiz. A ilustração no livro infantil. Belo Horizonte: Editora Lê, 1998

DOMICIANO, Cássia Letícia Carraro. Livros infantis sem textos: dos pré-livros aos livros ilustrados. Tese de doutorado pela Universidade do Minho. Guimarães, 2008.

HOLLIS, Richard. Design gráfico: uma história concisa. São Paulo: Martins Fontes, 2001.

HUNT, Peter. Crítica, teoria e literatura infantil. São Paulo: Cosac Naify, 2011.

JOLY, Martine. Introdução à análise da imagem. Campinas: Papirus, 2000.

KNAUSS, Paulo. O desafio de fazer história com imagens: arte e cultura visual. ArtCultura, Uberlândia, MG, v.8, n.12, p. 97-115, 2006.

MELLO, Roger. Contradança. São Paulo: Companhia das Letrinhas, 2011.

SANTAELLA, Lúcia \& NÖTH, Winfried. Imagem: cognição, semiótica, mídia. São Paulo, lluminaras, 1999.

SANTOS, Maria \& NAVAS, Ana. Distúrbios da leitura e da escrita: teoria e prática. Barueri: Editora Manole, 2002.

SARDELICH, Maria Emília. Leitura de imagens, cultura visual e prática educativa. Caderno de Pesquisa, São Paulo, SP, v.36, n.128, p. 451-472, 2006.

WADSWORTH, Barry. Inteligência e Afetividade da Criança na Teoria de Piaget, 5a ed. São Paulo: Pioneira. 1997.

WERNECK, Regina Yolanda. A importância da imagem nos livros. In: SANDRONI, Laura C.; MACHADO, Luiz P. A criança e o livro. Guia prático de estímulo à leitura. São Paulo: Ática, 1986. 